\title{
On Bridging the Gap in the Sexual Behavior of the Sexes: The Mediating Role of Culture/Environment
}

\author{
Adedeji Julius Ogunleye ${ }^{1}$, Tosin Tunrayo Olonisakin ${ }^{2}$, Sulaiman Olanrewaju Adebayo ${ }^{3}$ \\ ${ }^{1}$ Department of Psychology, University of Uyo, Akwa Ibom State, Nigeria \\ ${ }^{2}$ Department of Psychology, University of Lagos, Lagos State, Nigeria \\ ${ }^{3}$ Department of Psychology, Ekiti State University, Ado Ekiti, Nigeria \\ Email address: \\ dr.ajogunleye@gmail.com (A. J. Ogunleye)
}

\section{To cite this article:}

Adedeji Julius Ogunleye, Tosin Tunrayo Olonisakin, Sulaiman Olanrewaju Adebayo. On Bridging the Gap in the Sexual Behavior of the Sexes: The Mediating Role of Culture/Environment. Humanities and Social Sciences. Vol. 3, No. 2, 2015, pp. 88-95.

doi: $10.11648 /$ j.hss.20150302.14

\begin{abstract}
Sexuality is an important component of human life given its implication for sexual satisfaction, reproduction, egalitarianism and the continuity of the human race. The purpose of this paper is to present a review of the literature on cultural sex-role prescriptions for male control and female deference particularly in the Nigerian literature, and to demonstrate the implication of such for relationship satisfaction, sexually transmitted infections and egalitarianism, and the building of a virile society. In this article, we emphasize the socio-cultural specifics of the Nigerian society and its role in perpetuating power imbalance, sexual inequality and sexual in-expression between men and women.
\end{abstract}

Keywords: Sexual Behavior, Sex Differences, Egalitarianism, Culture/Environment, Socialization, Nigeria

\section{Introduction}

Pink for girls, blue for boys; dolls for girls, trucks for boys; girls are fragile, boys are strong; girls are dependent, boys are autonomous. These are some of the basic differential treatment and assumed sexual characteristics of the sexes that begin very early in childhood and the beginning of the reinforcement of the double standard for the sexes that persists throughout the process of socialization. Socialization is a continuous process throughout the lifetime of an individual wherein norms, roles and values are passed down from generation to generation. Such norms, roles, and values however, often emphasize sex differences and permeate cultures.

From childhood people are ingrained with a strong sense of what and how males and females are supposed to be and act. All newborns look alike after birth, but what can help an onlooker to determine the sex of the child at first glance is the way the child is dressed and the color of the dress. From this point forward, sex-role socialization begins. As these infants develop, other cultural norms reinforce these differences. Boys are given toys different from those given to girls and are told to behave differently from girls. Differential reinforcement (the balance of anticipated or actual rewards and punishments that are consequences of behavior) and corrections from parents and other caregivers such as "you can't talk like that, don't you know you are a girl"; or "don't cry, boys are not supposed to cry" gradually tells boys and girls how they ought to behave. In essence, boys should be masculine while girls should be feminine. While masculinity is associated with assertiveness, bravery, independence and risk-taking, femininity is associated with deference, submissiveness, sensitivity, nurturance and supportiveness. Therefore, women are positioned as passive objects of male sexual desire, want and need. The effects of such differential treatment, expectations and rewards will be visible throughout the life-time. This emphasizes the magnitude of differences in sex-role socialization and forms the onset of sexual double standards.

The conclusion from the above is that sex differences in behavior are largely a product of the culture or environment in which the individual is socialized. As socialization continues, culture spells out thoughts, behaviors, feeling, careers, house chores and etiquette for the sexes which are displayed in parents, peers, friends, media, religious preaching, societal laws and norms. Ensuring that members of the society comply with its dictates instigates mechanisms of social control and punishment for those that deviate from the norm. Hence, the society spells out its rules of conduct 
and puts in place mechanisms that perpetuate this conduct. Culture, the way of life of a society, is a primary factor and system through which sex stereotype is therefore maintained.

Valentini (2005) sees culture as the depository of beliefs, knowledge, values, experience, meanings, hierarchies, religion, timing, roles, worldview, physical objects and possessions acquired by a large group of people in the course of the generations through individual and group efforts. Deresky (2003), on the other hand, views culture as comprising those shared values, assumptions, understanding and goals that are acquired from one generation, forced by the current generation and transferred to consecutive generations.

Our culture defines which behaviors are appropriate, right or wrong; it defines boundaries, moulds our beliefs and behaviors through its elements such as religion, language, values, dressing and through its institutions like the family, school, mass media and marriage. Culture permeates every human action or behavior or endeavor, be it career choice, eating, dressing, talking, sleeping, perception, likes and dislikes and sexual behaviors.

Of all these cultural influences, the domain of sexuality has received a great deal of attention (Adebayo \& Olonisakin 2014a; Adebayo \& Olonisakin, 2014b; Aluko, 2011; Caldwell, Orubuloye \& Caldwell, 1991; Orubuloye, Caldwell and Caldwell, 1995; Orubuloye, Oguntimehin and Sadiq, 1997; Isiugo-Abanihe, 1994; 2000; Oyekanmi, 1999; Wusu \& Isiugo-Abanihe, 2008) perhaps because it is directly related to the physical and psychological health and functioning of an individual.

Despite the attention however, particularly as it relates with physical and psychological health and well being; equality between the sexes in Nigeria seem to be evasive or at its low ebb. For example, fewer women are involved in the decision making processes in almost all works of life in the country. Where the women are involved, their participations are second fiddled and at a gladiatorial level, and the women are often looked down on; or even labeled as rebellious or whores who will rather not want to be controlled by men. Worst still, most of such women in positions of decision making seem to be single mothers living outside matrimonial homes. If the saying that men and women are equally born, and the world clamor for an egalitarian society, is anything to go by therefore, it becomes expedient that attempts be made to look into the societal factors for inequality between the sexes with a view to bridging such gap. This paper serves as one of such attempts.

As has been mentioned elsewhere in this piece, sexuality is a vital aspect of human life and central to the continuous existence of the human race. It is a central aspect of who and what we are. It is one the basic human drives that contributes to physiological and psychological balance in the body. Our sexuality as humans is necessitated by the need to reproduce, to enjoy intimacy and passion, and to express our feelings. This makes sexuality a fundamental aspect of human existence. Rathus, Nevid and Fichner-Rathus (1993) captures it all when they said human sexuality is the way in which we experience and express ourselves as sexual beings and Spring (1999) emphasized this when she said it is an integral part of our personalities.

Various factors open us to our sexuality of which our sex, that is, the biological characteristic of being a male or a female is the starting point. The cultures in which we develop then imbibe in us sexual behaviors that should correspond to our sexes. According to Rutter and Schwartz (2000), majority of sexual behaviors are apt to reflect the cultural norm in general.

Various theories on human learning and cultural preservation and perpetuation provide a useful framework for understanding the sexual behaviors of men and women particularly in heterosexual relationship. Some of these theories are social learning theory by Bandura (1977) and gender schema theory by Bem (1981) among others. Bandura (1977) posits that we conform to the behaviors we observe in the society to obtain favorable consequences and avoid punishment. By observing the behaviors of others in true life and in the media, Bandura argued that children gain the knowledge that certain behaviors are rewarded and more appropriate in one sex than in the other. Similarly, Bem (1981) wrote that the process by which a person's behavior and perceptions come to reflect the society's prescription for his or her sex involves gender-schematic processing which she defines as "a generalized readiness on the part of the person to encode and to organize information, including information about the self, according to the culture's definition of maleness and femaleness". The society's emphasis and enforcement of such differences between the sexes leads to the formation and development of such gender-schema.

Both theories emphasize differential reinforcement as the society's way of ensuring that people conform to its dictates. Although some individuals rebuff or refuse to exhibit societal acceptable behaviors for own sex (Adebayo \& Olonisakin, 2014a; Bem, 1981; Haslanger, 1995; Stoljar, 1995), most people who conform to society's prescribed perfectionism aim to satisfy others by striving to fulfill those expectations (Flett, Hewitt, Oliver, \& Macdonald, 2002).

Acknowledging that there are cultural variations among societies, Hofstede (1991) proposed the concept of National culture. According to the scholar, national culture consists of the economic, social and political values that prevail in a particular nation which invariably characterize the way people live and work. In addition, the scholar identified five dimensions of national culture of which power distance is one. Power distance refers to the extent to which people of a society admit unequal distribution of power. Although, from a sociological point of view, Nigeria cannot be said to have a national culture given her multi-religious, multi-lingua, multi-ethnic character; nonetheless, Nigeria is a nation that acknowledges power distance; in particular, power distance between the sexes in sexual interaction. Although there are socio-cultural variations among Nigerians depending on their region or ethnic grouping, there are still generally held beliefs and attitudes which cut across geographic or ethnic affiliations. Among these beliefs is the belief that men and 
women should demonstrate different sexual behaviors (Adebayo \& Olonisakin, 2014a; Ogunleye, 2013). The power distance between the sexes is emphasized and reinforced by Nigeria's cultural elements. Such cultural elements include the followings:

- Religion: Nigerians are highly religious people whose religions emphasize power differentials between the sexes; more so in marriage (Adebayo \& Olonisakin, 2014a). These religions emphasizes woman's submissive role to the man in all things and some even permits polygamy for the man. Most people derive their moral values from their religion and the fact that our morals come from God provides an uncontested admittance of such morals. Because women seem to tend to have a stronger personal religious commitment than men, they show more adherences to religious dictates.

- Language: Inequality between the sexes is also emphasized by the various sayings, adages, proverbs and maxims of Nigerians regardless of their ethnic affiliations. For instance a man that is promiscuous earn the label "stud" while woman that is promiscuous earns the label "slut". The Yorubas in southwestern Nigeria often also say that a man can marry many wives but that it is forbidden for a woman to have more than one husband.

- Values: Nigerians have the values of respect for authority, hierarchy and patriarchy in which men are seen as the keepers of such authority and high up in such hierarchies. Men, due to the influential positions held in the society as husbands, fathers, priests, local and national leaders, are highly revered. The male child is believed as superior to a female child in most parts of Nigeria because after marriage, a female ceases to answer the father's name whereas the male child continues to answer such names and even bring in more members into the family; thereby subsisting and perpetuating the family names. Also, men are chiefly associated with work and public life while women are associated with the home life.

- Practice: Various practices such as the payment of bride price by the groom for the bride, attaching more value to the education of the male child than the female child, stereotyping certain jobs/careers for men (such as engineering, politics and so on) and for women (nursing, chef and so on), the emphasis on proper (clothing that should not expose the body) dressing for the female due to religious dictates and cultural perception that the body of a woman belongs to her husband/partner (future or present), the emphasis on the virginity of the woman at the point of marriage while encouraging the sexual prowess of the man, circumcision of the male being linked to bravery, maturity and improved sexual performance while that of the female is linked to the need to curb sexual appetite and promiscuity are also some of the cultural practices which emphasizes power distances between the sexes.
It is interesting to note a new emerging trend in sexual behaviors and relations in Nigeria however. Men and women's sex-roles are becoming more egalitarian over time. For instance, due to modernization, social and economic upheaval, some of the cultural practices mentioned above are no longer as potent as in the past. For example, male and female education is equally emphasized and both men and women now engage in jobs/careers that were, before, seen as the domain of the opposite sex. Nonetheless, the sexual double standards have not been fully eroded in Nigeria. Masculinity with regards to sexuality in Nigeria is still associated with domination of sexual decision making, risky sexual behavior such as not using condom during indiscriminate sexual practices and extra-marital affairs while femininity with regards to sexuality is associated with playing a passive, seductive, submissive and cooperative role (Adebayo \& Olonisakin, 2014b; Isiugo-Abanihe, 2000; Oladeji, 2008). Although Sanchez, Fetterolf and Rudman (2012) argued that women's objective account of their sexual behaviors will negate their proclaimed sexual submissiveness; however, empirical evidence in Nigeria suggests that the traditional sexual roles continue to dominate heterosexual relations revealing women to take a submissive role in sexual relations with their husband/partner (Adebayo \& Olonisakin, 2014a; Adebayo \& Olonisakin, 2014b; Isiugo-Abanihe, 1994; 2000; Oyekanmi, 1999). These findings lend credence to the sexual script theory of Simon and Gagnon (1987) which suggests that in heterosexual relationships, majority of sexual behaviors tend to reflect the cultural norms in general.

Certain socio-cultural specifics of the Nigerian society contribute to the perpetuality of the sexual double standard despite increasing efforts at equality of the sexes in other facets of life. The Nigerian society has put in social mechanisms or control to check behaviors that do not conform to the sexual norm for the sexes. These include ridicule, loss of friends and family support, snickering and disdainful looks or exclusion from certain social circles. Sexual behaviors that deviate from the norms may attract negative comment from one's partner. For instance, a man who prefers the woman to take the lead role during sexual intercourse or who decides to have only one sexual partner may be seen as contradicting the image of the male as powerful and dominating force in sexual activity and may even have his virility and prowess questioned. On the other hand, a woman who wants to take the lead role may be accused of having previous or too many sexual experiences or as being unfeminine. Hence, women's account of their sexual experience tend to be described in terms of what happened to, or was done to, them rather than what they did in sexual relationships; of which the opposite is for men. Also, because women tend to attach importance to their ability to secure and maintain relationships as emphasized in Nigeria's reverence of the marriage institution and remaining in it; women, particularly those of marriageable age, so as to avoid ridicule and castigation, may comply or endure the sexual situations or relations with their partner; albeit unsatisfying. Hence, it is likely that women who show 
control or are outspoken in other areas may comply with their partner's decision regarding sex.

As an example, Wusu and Isiugo-Abanihe's (2008) study to examine sexual negotiation between married couples in Ogun, Southwestern Nigeria found out that the cultural climate of the society preconditions women's mind to always wait for men to initiate sex. Similarly, Isiugo-Abanihe, (2000) in a study of more than 3,000 urban Nigerian couples found out that while men may not necessarily dominate decision making, they still wield more power than women do. Men and women were interviewed on who decides such matters as family size and when to have sex. In this study, close to $60 \%$ of men said that they decide and $40 \%$ to $50 \%$ of women agreed that men decide (Isiugo-Abanihe, 2000). The study also revealed that the more women endorsed attitudes towards traditional sexual roles, the more likely they were to engage in passive sexual behavior; whereas the more men endorsed these roles, the less likely they were to engage in passive behavior. Also Adebayo and Olonisakin (2014a) in a study using participants generated from a federal university in Nigeria found men to be higher than women in selfefficacy in sexual negotiation. Hence, it can be concluded that adherence to sexual stereotype engenders a vicious cycle in which people are punished for oddness, which compels them to comply with sex stereotypes, which then strengthen the stereotypes as also noted by Sanchez at al., (2012). Nevertheless, some studies also suggest that men and women step out of the cultural script of male dominance and female passivity (Aluko, 2011; Caldwell, Orubuloye \& Caldwell, 1991; Wusu \& Isiugo-Abanihe, 2008). For instance, Wusu \& Isiugo-Abanihe, (2008) found that in homes where there is frequent interpersonal communication, women are more likely to negotiate sexual advances with their spouses. Education and socio-economic status was found to be directly associated with such ability and acceptance of sexual negotiation between partners (Aluko, 2011; Wusu \& IsiugoAbanihe, 2008))

Since, sexuality is an integral part of human existence, how healthy a nation is has a lot to do with the sexual health of her citizens. Cultural prescriptions for masculinity and femininity in sexuality have varied implications for the individual and by extension, the nation. Such implications can be in one or both of two ways: psychological and physiological.

\section{Implications of the Sexual Double Standard}

\subsection{Psychological Wholeness}

In the development of the self-concept, Roger (1959) emphasized the environment. He believed that the essential element in one's environment that helped personal growth is unconditional positive regard (being accepted without judgment). Those raised in an environment of unconditional positive regard have the opportunity to fully actualize themselves and not develop incongruence (gap) between the real self (the genuine self without environmental impositions) and the ideal self (the self that gives up the real self to meet the approval of others and imposed standards of the environment). Such gap or incongruence between the real self and the ideal self and the constant effort of trying to bridge such gap, according to Rogers, can lead to the development of psychopathology. Likewise, Jack (1999) asserted that people prone to self-silencing are those who, in order to maintain their relationships and obtain the approval of significant others, keep their misgivings or worries, feelings or true desires to themselves. According to Jack, a sense of inadequacy and self-scolding results from believing and striving to uphold societal expectations and obligations of the ideal individual and sadly for the individual, such can cause illness. The emphasis of Rogers and Jack is that a fully functioning person is the one who is free to express him or herself without fear of being sanctioned. Since how men and women ought to behave in sexual relationships are dictated by the environment, this may prevent them from truly expressing to each other what they feel or how they want sexual intercourse to be, or be opened to different sexual experiences with their partner. Strife and sexual dissatisfaction may characterize the relationship in which one or both partner experiences such. It may be needless here emphasizing again that psychopathology is a serious social problem that hampers national growth, stability and sustainability.

\subsection{Sexual Satisfaction and Relationship Satisfaction}

Vitality for long-term heterosexual relationships is found in sexual activity (Elliot \& Umberson, 2008). The sexual part of a relationship is often essential to keeping it strong and healthy. Sexual intercourse between men and women is one of the physical ways of expressing affection for each other. Indeed most relationships may not endure without it. Various studies have linked the sexual behaviors of men and women to general well-being, sexual satisfaction and relationship satisfaction (Davison, Bell, LaChina, Holden \& Davis, 2009; Elliot \& Umberson, 2008; Henderson-King \& Veroff, 1994; Kiefer \& Sanchez, 2007; Sanchez, Kiefer, \& Ybarra, 2006). For instance, Kiefer \& Sanchez (2007), and Sanchez et al. (2006) found that the submissive sexual behavior of women predict lower sexual autonomy (the extent to which one perceives oneself to be in control and be able to exercise choice in their sexual encounter) and ultimately sexual dissatisfaction which, in turn, predicts reduced satisfaction among their sexual partners.

Sexual intercourse embodies a fundamental way in which people can express love and care for one another. Of course, it is not the only way of showing affection, but sex is culturally emphasized as an indication of love and marital harmony, for married couples (Elliot \& Umberson, 2008). The Nigeria nation is plagued with cases of divorce (Ukemena, Uzoaru, Olayiwola \& Ahmed, 2014; "Lawyers lament", 2012) and adultery has been implicated (Ukemena, Uzoaru, Olayiwola \& Ahmed, 2014). Given the higher rate of infidelity among men (Exner, et al., 2009; Isiugo-Abanihe, 
1994) therefore, it is possible that lack of sexual gratification and satisfaction with sexual intercourse with one's spouse is a causal factor for such divorce and infidelity. When men and women find it difficult to achieve satisfaction in sexual intercourse with their partners because of partner's unwillingness to be experimental or inventive, they may seek such fulfillment with other partners outside their primary relationship; even prostitutes who may not be bound by societal expectations of normative sexual behavior for the sexes.

\subsection{Spousal Violence}

The power inequality between men and women is most pronounced in sexual relationships. Adherence to sex-role prescription for sexual behavior may be a causal factor in the rape of women by men. Rape constitutes psychological abuse because it involves behaviors whose consequences or aftermath can be traumatic for the recipient of such behaviors and which occurs in situations of power imbalance between the parties (Dutton, 1994; Roland \& Daniel, 2000; Thompson \& Kaplan, 1996). It is said that in patriarchal societies, when men display physical violence against their wives, such behaviors are seen as "normal psychological and behavioral patterns of most men" (Bograd, 1988) and as fulfilling the cultural recommendation of male dominance and female subordination (Dobash, \& Dobash, 1979; Walker, 1989). The cases of rape in Nigeria are rampant. Needless to say is what kind of effect rape would have on the relationship between the partners, it is even worse when the wife do not characterize the mistreatment as abusive but see it as a demand for his rights by the man. Not recognizing these actions as abusive may be a coping mechanism to minimize or tolerate such abuse, the cumulative effect of such, overtime, can be very damaging physically and psychologically.

\subsection{Sexually Transmitted Infections}

Perhaps the most debilitating implication of sexual-role prescription is its implication for sexually transmitted infections (STIs) and unwanted pregnancy. Information regarding STIs and their mode of transmission is everywhere in the nation, be it in the hospital, on billboards and other mass media. However, Nigeria is said to contain one of the most explosive epidemic of HIV/AIDS in West Africa. About 3.1 million persons are living with HIV in Nigeria (National Agency for the Control of Aids [NACA], 2011) while adolescents represent the majority of all abortion seekers with almost $14 \%$ of all abortions occurring in adolescents under the age of 20 years (World Health Organisation [WHO], 2006). Notwithstanding the frequent and widespread coverage given to HIV/AIDS and unwanted pregnancy, the disease is still spreading. Teenagers are still getting pregnant, women are still succumbing to unwanted sexual relations and men are still taking sexual risks (Adebayo \& Olonisakin, 2014b).

Consistent with traditional sexual script, it is believed that men are more sexual than women and that they have an urgent need for sex which is the duty of the woman to fulfill. Men may also comply with unwanted sexual relations as a way of acquiring and retaining social standing and proving their masculinity. This means that men are encouraged to take chances that can increase their risk of contracting sexually transmitted infections; thereby also contributing to high number of unwanted pregnancies. This power relation in heterosexual relationships has implications for both men and women in attempting to negotiate safe-sex practices. Women are at greater risk for HIV/AIDS than men because of their biological make-up; their increased vagina surface area. It is estimated that unlike men, women are eight times more likely to contract HIV/AIDS from a man than for a man to contract it from a woman (Neely-Smith, 2009). The use of condom provides protection against STIs and unwanted pregnancies. However, it is a male-controlled method of protection and women are relegated to the lesser position of negotiating its use. Given the higher rate of infidelity among men (Exner, et al., 2009; Isiugo-Abanihe, 1994) and women's greater vulnerability when exposed to sexually transmitted infection (Neely-Smith 2009); it is evident that women are placed at risk of STIs, particularly because cultural sex- role expectations dictates a less active role in sexual situations in relation to the man, particularly because men are prone to having multiple sexual partners (Exner, et al., 2009; IsiugoAbanihe, 1994).

\section{Recommendations}

A lot of misdemeanor has been perpetrated in the name of culture. Limiting the freedom of individuals for sexual expression is a demonstration of such misdemeanor, while STIs, unwanted pregnancies, sexual dissatisfaction, divorce and infidelity and relationship dissatisfaction are examples of the consequences of such misdemeanor. While cultural sexrole dictates set the stage for men and women's sexual relations, this is not to say that they never act to contradict the sexual script of male assertiveness and women submissiveness. Evidences from Nigerian and other national scholars also suggest that men and women sometimes step out of the cultural script of male dominance and female passivity. The reason for such discrepancy could be that most people's adherence to traditional sexual script, particularly in Nigeria, is a matter of conforming to ingrained sexual values and not to social reality, the unwillingness to test new realities. What this means is that people may automatically assume traditional sexual roles for the sexes without testing the specific reality that applies to their own relationship with their partners; that is, their own partners' preferences. Displaying such behavior to one's partner may instigate the process or mechanism of self-fulfilling prophecy (behaviors that leads others to behave in ways that confirms our expectations of them) in the partner which then establishes and perpetuates the norm for sexual relations between the partners. Perhaps when partners in heterosexual relationship are able to discuss with each other how they want sexual 
activities to be like, both partners will be willing to accommodate what the other wants. To capture it all, talking helps. And Ogunleye and Oke (2012) have found out that sexual self disclosure can be instrumental to an enduring and satisfying relationship among dating partners.

Peculiar to studies that have found women to have control or be able to negotiate sex with their husbands is the education and socio-economic standing of the men and women. Women in Nigeria face a lot of socio-economic constraints primarily because of the cultural expectations from the woman as a wife, mother, home-maker, and even, sometimes as breadwinners. Hence, we have a culture in which excessive social expectations are placed on the shoulders of women. Women who have few or no profitable skills or viable employment can be forced into situations of dependency on a man where she might have little or no say in sexual matters. Having to depend on a man financially may mean that the woman cannot control when and with whom she has sexual intercourse and she may have to exchange sex for material favor in order to survive. Women empowerment through provision of education and skills with which they can provide for themselves or support their family will prevent them from being over-reliant on their male friends or husbands. Education is also positively related to men's view that their wives can negotiate their sexual demands. This indicates that there will be more open and equal marital relations among better educated couples. When partners in a relationship are able to openly express their feelings regarding their sexual needs, desires and demands rather than silence themselves; when they show unconditional positive love and needs regardless of whether such needs negate the norm, such a couple have the tendency to have relationship satisfaction, sexual satisfaction, relationship longevity and general wellbeing.

Another social dimension of the sexual double standard in Nigeria that restrains women's expression of their sexuality is that while men may discuss or even boast about their sexuality, this is not so for women. While men brag about their sexuality and take on multiple partners, a woman who does that is labeled promiscuous. Men in the categories are termed as study and staunch while the women are seen as 'sleaze ball' or 'slag' tossed around. The sanctioning of men having multiple sexual partners while criticizing women that do implies a relativist perspective in which the act is only wrong when it is performed by a woman. When the act of having multiple sexual partners is approached from an idealistic perspective, (that is, it is wrong for both men and women because of its implication for STIs) and emphasized by culture, perhaps it will go a long way in helping to curb the spread of STIs particularly HIV/AIDS in Nigeria (since sexual intercourse is the prevalent mode of transmission for STIs).

Finally, Bem (1977) argued that people who incorporate feminine and masculine traits are better equipped to operate in the society because they have behavioral flexibility and adaptability to function. Thus, sex-role socialization particularly with regards to sexual behaviors should not follow rigid sex-typing. Boys and girls should be oriented to adjust to situation as they come; looking for situationspecifics that can be harnessed for good. Attitude-behavior consistency theory tells us that personal norms, (how people believe significant others or society expects them to behave, think or feel) to a large extent, dictates both people's attitude and behavior. When our cultural practices, education, values, languages and so on emphasizes and sanction equal power for men and women in their sexuality, it will go a long way in authorizing equality in the minds of the people and considerably bridge the gap in the sexual behavior of the sexes for a healthy living and egalitarianism.

\section{References}

[1] Adebayo, S. O., \& Olonisakin, T. T. (2014a). Influence of sex and gender-role on self-efficacy in sexual negotiation. Online Journal of Social Sciences Research, 3(7): 181-188.

[2] Adebayo, S. O., \& Olonisakin, T. T. (2014c). Influence of sex and gender-role on personal control. International Journal of Academic Research in Business and Social Sciences, 4(8): 111-121. doi: 10.6007/IJARBSS/v4-i8/1077.

[3] Adebayo, S. O. \& Olonisakin, T. T. (2014b). Influence of sex and gender-role on safe-sex behaviours. Global Science Research Journals, 2(4): 051-055.

[4] Akers, R. L., \& Sellers, C. S. (2004). Criminological theories: Introduction, evaluation and application. Los Angeles, California: Roxbury Publishing Company.

[5] Aluko, Y. (2011). Women's sexual and health rights in normal unions in Ibadan, Nigeria. Social \& governance policy research department, Nigerian institute of social and economic research (NISER) Ojoo-Ibadan, 1-15.

[6] Bandura, A. (1969). Principles of behavior modification.NewYork: Holt, Rinehart\&Winston.

[7] Bem, S. L. (1977). On the utility of alternative procedures for assessing psychological androgyny. Journal of Clinical and Consulting Psychology, 45: 196-205.

[8] Bem, S. L. (1981). Gender schema theory: A cognitive account of sex typing. Psychological Review, 88(4): 354-364.

[9] Bograd, M. (1988). Feminist perspectives on wife abuse: An introduction. In Bograd, M., \& Yllo, K. (Ed), Feminist perspectives on wife abuse. Beverly Hills: Sage Publishing.

[10] Caldwell, J.C., Orubuloye, I. O., \& Caldwell, P. (1991). The destabilization of the traditional Yoruba sexual system. Population and Development Review, 17: 229-262.

[11] Cassidy, G. L. (1997). Gender differences in perceived control over life (Masters thesis, University of Western Ontario, London, Ontario).

[12] Davison, S. L., Bell, R., LaChina, M., Holden, S. L., \& Davis, S. R. (2009). The relationship between self-reported sexual satisfaction and general well-being in women. Journal of Sexual Medicine, 2009. doi: 10.1111/j.17436109.2009.01406.x.

[13] Dobash, R. E., \& Dobash, R. P. (1979). Violence against wives: A case against the patriarchy. New York: Free Press. 
[14] Dutton, D. G. (1994). Patriarchy and wife assault: The ecological fallacy. Violence and Victims, 9: 125-140.

[15] Dworkin, S. L., \& O‘Sullivan, L. (2005). Actual versus desired initiation patterns among a sample of college men: Tapping disjunctures within traditional male sexual scripts. Journal of Sex Research, 42: 150-158.

[16] Elliot, S., \& Umberson, D. (2008). The performance of desire: Gender and sexual negotiation in long term marriages. Journal of Marriage and Family, 70(2): 391-406. doi: 10.1111/j-1741 -3737,2008-00489.x.

[17] Exner, T. M., Mantell, J. E., Adedokum, L. A., Udoh, I. A., Ladipo, O. A., Delano, G. E., (...) Akinpelu, K. (2009). Mobilising men as partners: The result of an intervention to increase dual protection among Nigerian men. Journal of Health Education Research, 24 (5): 846-854.

[18] Flett, G. L., Hewitt, P. L., Oliver, J. M., \& Macdonald, S. (2002). Perfectionism in children and their parents: A developmental analysis. In G. L. Flett \& P. L. Hewitt (Eds.), Perfectionism: Theory, research, and treatment (pp. 89-132). Washington, DC: American Psychological Association.

[19] Haslanger, S. (1995). Ontology and social construction. Philosophical Topics, 23: 95-125.

[20] Henderson-King, D. H., \& Veroff, J. (1994). Sexual satisfaction and marital well-being in the first years of marriages.Journal of Social and Personal Relationships, 11: 509-534.

[21] Hofstede, G. (1991). Cultures and organizations: Software of the mind. New York: McGraw Hill.

[22] Isiugo-Abanihe, U. C. (1994). Extramarital relations and perceptions of HIV/AIDS in Nigeria. Health Transition Review, 4, $111-125$.

[23] Isiugo-Abanihe, U. C. (2000). Reproductive motivation and family size preference among Nigerian men. Studies in Family Planning, 25(3): 149-161.

[24] Jack, D. C. (1999). Ways of listening to depressed women in qualitative research: Interview techniques and analyses. Canadian Psychology, 40: 91-101.

[25] Jack, D.C. (1991). Silencing the self: Women and depression. Cambridge: Harvard University Press.

[26] Kiefer, A. K., \& Sanchez, D. T. (2007). Scripting sexual passivity: A gender role perspective. Personal Relationships, 14: $269-290$.

[27] Kiefer, A., Sanchez, D. T., Kalinka, C. J., \& Ybarra, O. (2006). How women's nonconscious association of sex with submission relates to their subjective sexual arousability and ability to orgasm. Sex Roles, 55: 83-94.

[28] Lawyers lament high rate of divorce in Nigeria on. (2012, June 24). Vanguard News.

[29] Melendez, R. (n.d). Center for Research and Educationon Gender and Sexuality Latina and African-American women's experiences with gender, religion and HIV prevention.pp1-3.

[30] National Agency for the Control of Aids (2011). Preventing HIV/AIDS.
[31] Neely-Smith, S. L. (2009). Influence of self-esteem and selfsilencing on self-efficacy for negotiating safer behaviours in urban Bahamian women. The Journal of Multicultural Nursing and Health. Retrieved from http://findarticles.com/p/articles/ml_qu3919/is_200401/al_n93 61181/print?tag=artbody:col2.

[32] Ogunleye, A. J. (2013). Sex, sex-role orientation, personality and sexism in Nigeria. In R. I. Ako-Nai (ed.), Gender and Power Relations in Nigeria (Pgs. 123-139). New York: Lexington Books

[33] Ogunleye, A. J. \& Oke, O. S. (2012). Effect of sexual self assertiveness and sexual self esteem on sexual self disclosure among heterosexual adolescents in Nigeria. Elixir Journal of Social Science, 47(2012): 8817-8820.

[34] Oladeji, D. (2008). Gender roles and norms factors influencing reproductive behaviour among couples in Ibadan, Nigeria. Anthropologist, 10(2): 133-138.

[35] Orubuloye, I. O., Caldwell, J. C., \& Caldwell, P. (1995). The cultural, social and attitudinal context of male sexual behaviour in urban Southwestern Nigeria. Health Transition Review 5: 207-222.

[36] Orubuloye, I. O., Oguntimehin, F., \& Sadiq, T. (1997). Women role in reproductive health decisionmaking and vulnerability to STD and HIV/AIDS in Ekiti, Nigeria. Health Transition Review (Supplement), 7: 329-336.

[37] Oyekanmi, F. A. D. (1999). Current themes in population studies. In L. Olurode, \& O. Soyombo (Eds), Sociology for beginners (pp 165-190). Lagos: NIDD Limited.

[38] Rathus, A. R., Nevid, J. S., \& Fichner-Rathus, L. (1993). Human sexuality: In a world of diversity. Boston: Allyn and Bacon.

[39] Rogers, C. (1959). A theory of therapy, personality relationships as developed in the client-centered framework. In (Ed.) S. Koch. Psychology: A study of a science (Vol. 3): Formulations of the person and the social context. New York: McGraw Hill.

[40] Roland, M. D., \& Daniel, O. K. (2000). Psychological Abuse in Violent Domestic Relations. New York: Springer Publishing Company.

[41] Rutter, V., \& Schwartz, P. (2000). Gender, marriage and diverse possibilities for cross-sex and same-sex pairs. In D. H. Demo, K. R. Allen, \& M. A. Fine (Eds.), Handbook of family diversity (pp. 59-81). New York: Oxford University Press.

[42] Sanchez, D. T., Fetterolf, J. C., \& Rudman, L. A (2012). Eroticizing inequality in the United States: The consequences and determinants of traditional gender role adherence in intimate relationships. Sexuality and Gender Role, 2012: 1-54.

[43] Sanchez, D. T., Kiefer, A. K. \& Ybarra, O. (2006). Sexual submissiveness in women: Costs for sexual autonomy and arousal. Personality and Social Psychology Bulletin, 32(4): 512-524.

[44] Simon,W., \& Gagnon, J. H. (1987). A sexual scripts approach. In J. H. Geer \&W. T. O'Donohue (Eds.), Theories of human sexuality (pp. 363-383). New York: Plenum.

[45] Simon. W., \& Gagnon, J. H. (1987). A sexual scripts approach. In Geer J. H., \& O'Donohue, W. T. (eds.). Theories of human sexuality, Plenum, New York. 
[46] Spring, L. M. (1999). Human sexuality.

[47] Stoljar, N. (1995). Essence, identity and the concept of woman. Philosophical Topics, 23: 261-293.

[48] Thompson, A. E., \& Kaplan, C. A. (1996). Childhood emotional abuse. British Journal of Psychiatry, 168(2): 143-8.

[49] Ukemena B., Uzoaru, S., Olayiwola, A., \& Ahmed, U. (2014, February 1). Adultery: The reason behind high divorce rate. Leadership Newspaper.

[50] Valentini, C. (2005).The European Odyssey: Communication of cultures vs. cultures of communication, paper presented at the First European Communication Conference Fifty years of communication research in Europe: Past and future, Amsterdam.
[51] Walker, L. (1989). Psychology and violence against women. American Psychologist, 44(4):S 695-702.

[52] World Health Organisation (2006). Sexual and reproductive health of women living with HIV/AIDS. Retrieved from http:www.who.int/hiv/en.

[53] Wusu, O., \& Isiugo-Abanihe, U. C. (2008). Understanding sexual negotiation between marital partners: A study of Ogu families in southwestern Nigeria. African Population Studies, 23(2).

[54] Youmans, E. A. (2001). Gender-related traits, sexual self efficacy, importance of relationship and the relationship to college women's condom use (Doctoral dissertation submitted to the Seton Hall University). 